\title{
Calibration and sequential updating of a coupled hydrologic-hydraulic model using remote sensing-derived water stages
}

\author{
M. Montanari ${ }^{1}$, R. Hostache ${ }^{1}$, P. Matgen ${ }^{1}$, G. Schumann ${ }^{2}$, L. Pfister ${ }^{1}$, and L. Hoffmann ${ }^{1}$ \\ ${ }^{1}$ Centre de Recherche Public - Gabriel Lippmann, 4422, Belvaux, Grand Duchy of Luxembourg \\ ${ }^{2}$ School of Geographical Sciences, University of Bristol, BS81SS, UK
}

Received: 24 September 2008 - Published in Hydrol. Earth Syst. Sci. Discuss.: 19 November 2008

Revised: 26 February 2009 - Accepted: 10 March 2009 - Published: 18 March 2009

\begin{abstract}
Two of the most relevant components of any flood forecasting system, namely the rainfall-runoff and flood inundation models, increasingly benefit from the availability of spatially distributed Earth Observation data. With the advent of microwave remote sensing instruments and their all weather capabilities, new opportunities have emerged over the past decade for improved hydrologic and hydraulic model calibration and validation. However, the usefulness of remote sensing observations in coupled hydrologic and hydraulic models still requires further investigations. Radar remote sensing observations are readily available to provide information on flood extent. Moreover, the fusion of radar imagery and high precision digital elevation models allows estimating distributed water levels. With a view to further explore the potential offered by SAR images, this paper investigates the usefulness of remote sensing-derived water stages in a modelling sequence where the outputs of hydrologic models (rainfall-runoff models) serve as boundary condition of flood inundation models. The methodology consists in coupling a simplistic 3-parameter conceptual rainfall-runoff model with a 1-D flood inundation model. Remote sensing observations of flooded areas help to identify and subsequently correct apparent volume errors in the modelling chain. The updating of the soil moisture module of the hydrologic model is based on the comparison of water levels computed by the coupled hydrologic-hydraulic model with those estimated using remotely sensed flood extent. The potential of the proposed methodology is illustrated with data collected during a storm event on the Alzette River (Grand-
\end{abstract}

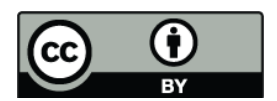

Correspondence to: M. Montanari (montanar@lippmann.lu)
Duchy of Luxembourg). The study contributes to assess the value of remote sensing data for evaluating the saturation status of a river basin.

\section{Introduction}

Over the last decade, many studies demonstrated that spatial information on the distributed physiogeographical characteristics and hydrologic responses of river basins can be gained from remote sensing observations. Taking into account satellite data in flood forecasting systems has the potential of significantly improving model performances. Indeed, the list of Earth Observation-derived products that are potentially useful in watershed modelling is long, including, most notably, precipitation fields, land use maps, digital elevation models, maps of snow cover, soil moisture, flood extent, vegetation cover and evapotranspiration. The requirements, with respect to imaging frequency, spatial resolutions and accuracy, strongly depend on the hydrologic variables to be monitored and the basin characteristics to be mapped. Whereas some basin characteristics such as land use and topography can be retrieved from a limited amount of images, the temporal variations of soil moisture, flood extent and snow cover implicate that the corresponding data need to be provided at a daily or at least weekly basis in order to be routinely used in forecasting systems.

Recent studies on integrating remote sensing observations of floods with hydrodynamic models investigated the potential for calibrating friction parameters in flood models (e.g. Aronica et al., 2002; Mason et al., 2003; Werner et al., 2005). In the same general context, Schumann et al. (2007a) demonstrated the potential of Earth Observation data to understand

Published by Copernicus Publications on behalf of the European Geosciences Union. 
and improve model structures by comparing remote sensingderived water stages along a river reach with simulated water surface lines.

Here we intend to introduce a new approach which consists in calibrating and sequentially updating a coupled hydrologic-hydraulic model using remotely sensed flood information. Surface water monitoring via remote sensing of flooded areas allows assessing the ratio between storm runoff and total rainfall, thereby providing a means for correcting volume errors in hydraulic models. The latter stems from forcing term errors (i.e. streamflow at the boundaries of the model domain). Andreadis et al. (2007) and Pappenberger et al. (2006) showed that the uncertainties associated with boundary conditions have a significant impact on inundation prediction accuracy. Moreover, they showed that remote sensing-derived water stages were useful to correct inflow data, thereby improving the skill of the hydraulic models. The dominant practice in hydraulic modelling consists in using recorded hydrographs as boundary conditions. In that case the uncertainty of the boundary condition depends on the accuracy of the stage-discharge relationship. In ungauged catchments, the associated uncertainty is increased significantly because hydrologic models need to estimate streamflow at the upstream boundary. In order to be able to simulate hydrographs accurately, these models need to predict the partitioning of precipitation into infiltration and stormflow adequately. This distribution largely depends on antecedent moisture conditions. Pfister et al. (2003) showed in a case study in a humid temperate region that stormflow coefficients may vary significantly depending on antecedent moisture conditions. These considerations have motivated many studies focusing on the remote sensing of soil moisture as the key environmental variable to be monitored in order to assess the saturation status of a river basin during storm events. As a result of all these efforts, there is nowadays a large variety of methods available to assess basin saturation via remote sensing of soil moisture.

There is no doubt that in the active microwave domain, Synthetic Aperture Radar (SAR) shows a high sensitivity toward water content in the first few centimeters of the soil. There are numerous studies that demonstrate this relationship (e.g. Quesney et al., 2000; Le Hégarat-Mascle et al., 2002; Zribi et al., 2005). In any discussion, it is, however, essential to distinguish between remote sensing of soil moisture at the plot and at the catchment scale. SAR backscattering is highly dependent on topography, soil texture, surface roughness, vegetation cover and soil moisture, meaning that soil moisture inversion is extremely difficult. Even in an ideal scenario where the effects due to topography, roughness and vegetation cover can be estimated, SAR generally fails to provide soil moisture variations at the plot scale (e.g. Wagner and Pathe, 2004; Walker et al., 2004). Only the averaging of the SAR signal over large areas seems to give acceptable estimates of the soil mean response. If the soil moisture response to the SAR backscatter can be separated from the vegeta- tion contribution and assuming that soil roughness does not need to be taken into account at catchment scale, one may obtain robust estimations of watershed averaged soil moisture indices (Le Hégarat-Mascle et al., 2002). But even with such a scenario, remote sensing can only be used to retrieve soil moisture in the first few centimeters of soil, whereas runoff generation is also largely controlled by deeper layers. Despite the aforementioned limitations, some studies (Pauwels et al., 2001; François et al., 2003; Matgen et al., 2005; Brocca et al., 2009) indicate that the integration of remote sensing observations of average basin soil humidity under certain conditions allows increasing the performance of rainfall-runoff models.

This paper considers an alternative approach to the existing studies mentioned above. Given the current limitations of active microwave sensors to map soil moisture, remote sensing of flooded areas may be regarded as an inviting alternative to assess basin saturation implicitly. As microwaves are reflected away from the sensor by smooth open water bodies, flood area detection via microwave remote sensing is rather straightforward (Smith, 1997). River stage can be estimated at the land-water interface using remote sensing derived flood boundaries in combination with topographic maps (e.g. Oberstadler et al., 1997; Schumann et al., 2007b; Hostache et al., 2006) even though associated uncertainties can be high (Schumann et al., 2008b). The appraisal of surface water storage within a given river reach can be done via the subtraction of the floodplain topography from the water surface. It can be argued that the surface water volume represents the aggregate response of a river basin to a storm event. Our assumption is that time series of remote sensing images of floods allow monitoring surface water volumes and, as a matter of fact, help to estimate effective rainfall during storm events (i.e. the part of total rainfall that is routed as stormflow towards the outlet). Knowing the total rainfall amount in the contributing area, it appears sensible to use these data sets for monitoring the time variation of runoff coefficients.

Our hypothesis will be tested by means of a case study that focuses on an application to the Alzette River in Luxembourg. Assuming that the study area is a data poor region, we will assess the ability of this methodology to provide reasonable estimates of discharge and flood extent with a limited amount of data at hand. Moreover, we will use this test site to establish the proof-of-concept of a routine remote sensingbased flood monitoring service as a means to monitor the saturation status of the river basin.

\section{General approach}

The methodology presented in this study aims at integrating remote sensing-derived information in a coupled hydrologichydraulic $(\mathrm{H}-\mathrm{H})$ model in order to improve model results by identifying and correcting the bias that may result from errors in the simulated inflow. The modelling sequence is 
performed by coupling a simplistic rainfall-runoff model and a 1-D flood propagation model so that the output of the former serves as input to the latter.

The analysis is carried out using two possible calibration approaches whereby the value of remote sensing data of floods in an aggregated modelling system will be assessed. Initially, an "all-at-once" calibration scheme is conducted. It consists in estimating both the hydrologic and the hydraulic model parameters in one go using SAR-derived water stages. Afterwards, a sequential model-updating scheme is performed in order to investigate the usefulness of remote sensing data for monitoring the saturation status of the river basin. This second approach first divides the parameters of the coupled H-H model into constants (i.e. parameters representing basin and river characteristics that can be transferred from one event to another) and time-varying (i.e. parameters whose values are event dependent). It is worth noting that the only time-varying parameter in this study is the stormflow coefficient, which implicitly represents the moisture status of the drainage area since the basin's antecedent moisture condition influences the partitioning of the total rainfall into infiltration and runoff. Then, model parameters are calibrated with field data collected during a well-documented flood event (reference event A) and the constants are transferred to another flood event (reference event B). Finally, the time-varying parameter, namely the stormflow coefficient, the value of which is expected to change from event A to any other event, is updated for event B using the SAR-derived water stages.

For both approaches, the calibration procedure is based on the Monte Carlo method that relies on repeated random sampling of parameter sets from within specified ranges to compute the results. Simulations of the coupled H-H model are performed with each set of parameters. Then, outputs provided by each simulation are compared to recorded observations. Using this kind of calibration process, it is possible to represent performances or errors of the model versus parameter values.

In order to establish the value of remote sensing-derived flood information for model calibration and updating, the outlined general approach will be applied in the framework of a case study in the Alzette river located in Luxembourg.

\section{Study area and available data}

The area of interest is located in the Grand Duchy of Luxembourg and includes the upper part of the Alzette River basin expanding from the head of the river, $4 \mathrm{~km}$ south of the French-Luxembourg border, to Mersch. Since this study deals with a loose H-H model sequence, two different substudy areas have been defined (Fig. 1): the drainage area to the stream gauge located in Pfaffenthal (Luxembourg City) and the river reach between Pfaffenthal and Mersch, respectively.

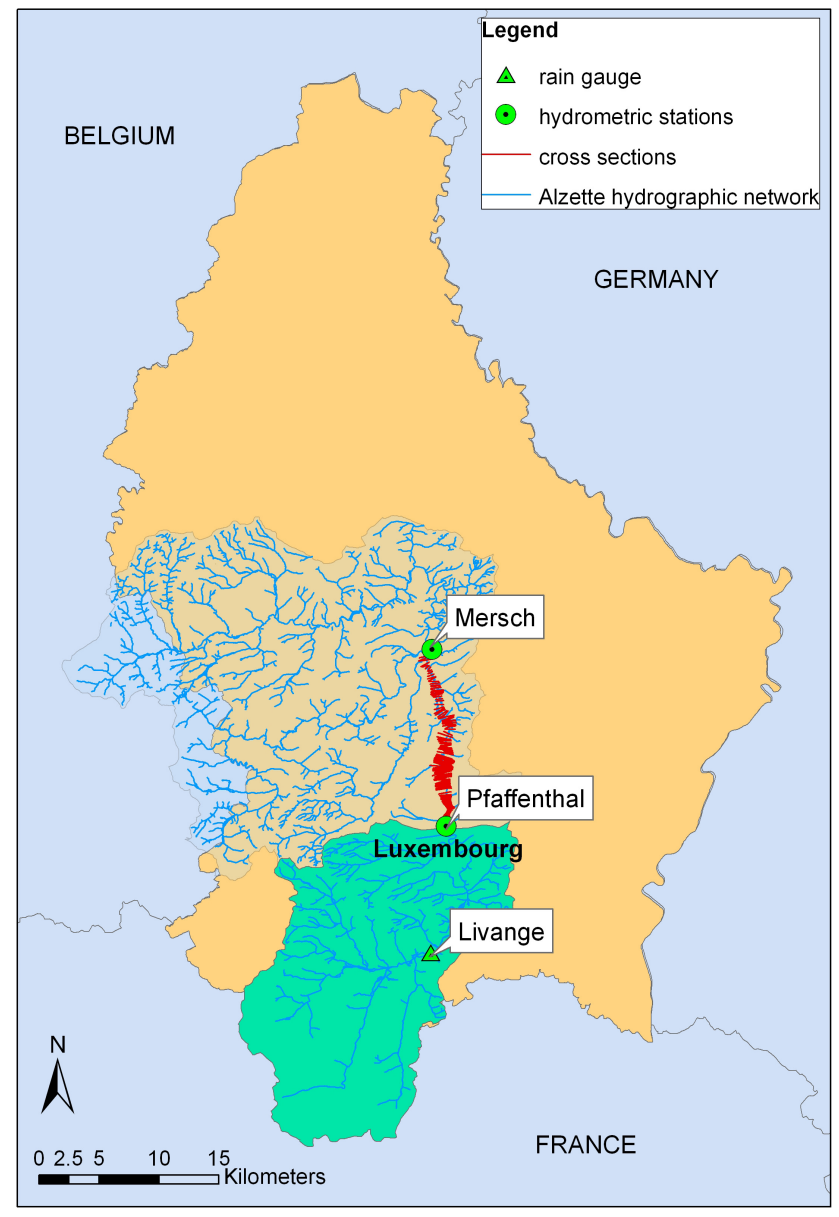

Fig. 1. The two study sites in the Alzette river basin: the $356 \mathrm{~km}^{2}$ drainage area down to Pfaffenthal (green patch) and the $19 \mathrm{~km}$ river reach between the hydrometric stations at Pfaffenthal and Mersch whose geometry is represented by the cross sections (red lines).

The first study area covers a surface of $356 \mathrm{~km}^{2}$ and is divided in cultivated land $(50 \%)$, urban centers $(22 \%)$ and woodland (28\%). The topography of the floodplain is characterized by a natural sandstone bottleneck, located near Luxembourg-city. Upstream of the bottleneck, the valley is up to $2.5 \mathrm{~km}$ wide, while in the Luxembourg sandstone the valley is only $75 \mathrm{~m}$ wide. Over the area, the geological substratum is dominated by marls on the left bank, while on the right bank it consists of limestone and sandstone deposits. Sand and gravel, as well as marls and clay alternate in the alluvial deposits covering the substratum. For further details about the physiogeographical characteristics of the Alzette river basin we cross-refer to van den Bos et al. (2006). A gauging station, operated since 1996, is located near the village of Livange, which provides cumulated precipitation amounts every $15 \mathrm{~min}$.

The second study area is the $19 \mathrm{~km}$ reach of the Alzette River between the gauging stations at Pfaffenthal and Mersch. Here, the river meanders in a relatively large and flat 


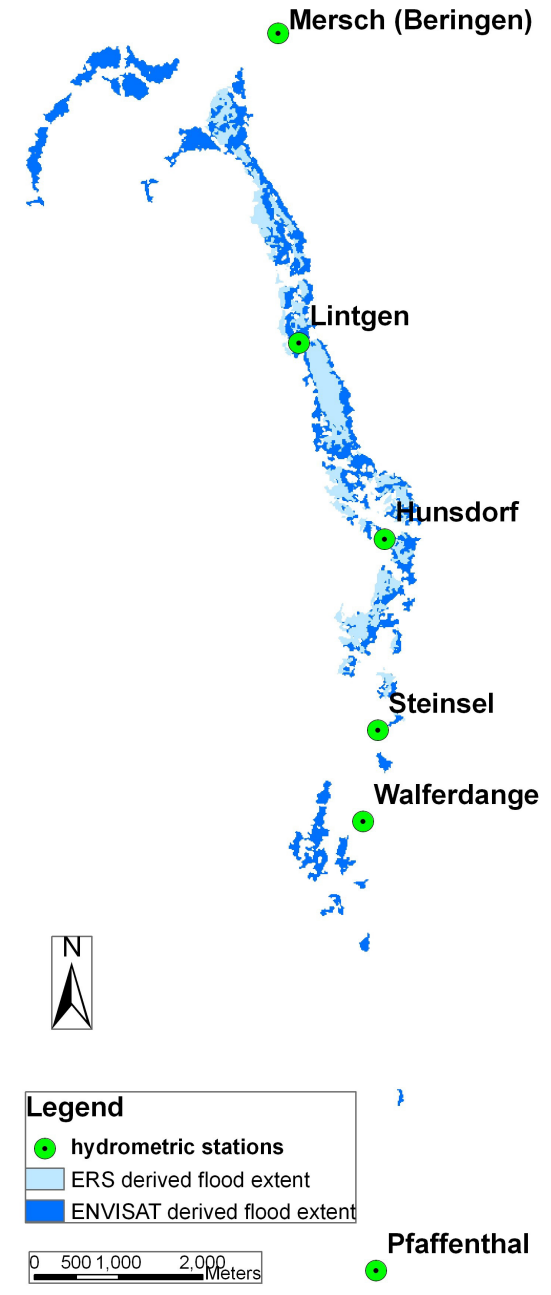

Fig. 2. Flood extents derived from the ENVISAT image (blue) and the ERS-2 image (light blue).

plain characterized by an average width of $300 \mathrm{~m}$ and a mean slope of $0.08 \%$. The average channel depth is $4 \mathrm{~m}$.

In this study the well-documented flood events that occurred in January 2003 and January 2007 have been investigated: the former, which is the focus of this study, is a high magnitude flood event with an estimated return period of 10 years and a peak discharge of $0.78 \mathrm{~mm} / \mathrm{h}$; the latter is a rather small (estimated return period of 4 years) flood event characterized by a peak discharge of $0.59 \mathrm{~mm} / \mathrm{h}$ recorded in Pfaffenthal .

The hydrometric data were recorded at a 15-min time-step at six stream gauges located in the villages of Pfaffenthal (upstream), Walferdange, Steinsel, Hunsdorf and Lintgen, but the stage hydrographs at Lintgen and Hunsdorf are only available for low water depths because of a temporary malfunctioning of the measurement system during high flows. Moreover, during the flood event the coordinates $(\mathrm{x}, \mathrm{y})$ of 84 flood extent marks have been measured on the ground with a GPS (about $5 \mathrm{~m}$ planimetric accuracy) and the maximum water level has been measured using a theodolite (altimetric accuracy around $\pm 2 \mathrm{~cm}$ ) at 7 points distributed across the floodplain. The altimetric data available are a LiDAR DEM with a $2 \mathrm{~m}$ spatial resolution and a $\pm 15 \mathrm{~cm}$ mean altimetric uncertainty, for the floodplain terrain elevations, and 200 bathymetric cross sections with a "theoretical" (some errors of more than $30 \mathrm{~cm}$ have been found during ground control survey) centimetric altimetric uncertainty, for the river channel elevations.

Two SAR images, acquired at two distinct stages of the 2003 flood event have been used in this study: one has been acquired by the ERS- 2 satellite during the rising limb of the flood wave; the second image was acquired by the ENVISAT satellite just after the flood peak. Figure 2 shows the flooded area covered by both images and Table 1 summarize the technical characteristics of the SAR instruments on board the satellites.

\section{Methodology}

\subsection{Coupled H-H model set-up}

As mentioned above, the modelling sequence consists of the loose coupling of a lumped conceptual event-based rainfallrunoff (R-R) model and a 1-D hydraulic model. The former represents the rainfall-runoff transformation occurring in the drainage area of the Alzette River up to Pfaffenthal and uses the rainfall recorded at the rain gauge located in Livange as input data. The latter simulates the propagation of the flood wave across the river channel and floodplain between the gauging stations in Pfaffenthal and Mersch. The link between the two models in the sequence is the discharge hydrograph computed by the R-R model since this is integrated with the hydraulic model as upstream boundary condition.

\subsubsection{Hydrologic component of the modelling sequence}

In this study, the stormwater runoff is simulated by the hydrologic model developed by Nash (1960). This conceptual model is based on two assumptions: the river basin can be described by an ensemble of $n$ linear reservoirs in series, all of them characterized by the same storage constant $K$; the flood hydrograph due to a single pulse of rain (defined by the Dirac conditions) is given by the Instantaneous Unit Hydrograph (IUH) Model (Sherman, 1932). Assuming an instantaneous unit rain pulse as input of the first reservoir, the output will be the IUH represented in Eq. (1), where the time $t$, as well as the storage constant $K$, is expressed in hours.

$u(t)=\frac{1}{K} e^{-\frac{t}{K}}$

The latter will be used as input of the next reservoir of the cascade, to whom the equation of mass balance will be applied in order to compute the output discharge. By iterating 
Table 1. Characteristics of the ENVISAT and ERS-2 images.

\begin{tabular}{llllllll}
\hline Satellite & Frequency & Band & Polarization & Incidence angle & Pixel spacing & Georeferencing error & Acquisition date \\
\hline ENVISAT & $5.3 \mathrm{GHz}$ & $\mathrm{C}$ & VV, VH & $35 \mathrm{deg}$ & $12.5 \mathrm{~m}$ & 1 pixel & $2.01 .2003,21: 57 \mathrm{GMT}+1$ \\
ERS-2 & $5.3 \mathrm{GHz}$ & $\mathrm{C}$ & VV & $23 \mathrm{deg}$ & $12.5 \mathrm{~m}$ & 1 pixel & $2.01 .2003,11: 00 \mathrm{GMT}+1$ \\
\hline
\end{tabular}

the procedure until the end of the cascade of reservoirs, the output discharge of the $n^{\text {th }}$ reservoir will be given by the following equation that represents the Nash IUH at the outlet of the basin:

$u(t)=\frac{1}{K \Gamma(n)}\left(\frac{t}{K}\right)^{n-1} e^{-\frac{t}{K}}$

In Eq. (2), $\Gamma$ is the Gamma distribution function depending on $K$ and $n$. By differentiating Eq. (2) with respect to $t$ and equating to zero in order to consider the peak discharge, $K$ is obtained as follows:

$K=\frac{t_{\mathrm{p}}}{n-1}$

Therefore, the Nash IUH is described by two parameters, namely the number of linear reservoirs $n$ and the recession time constant $t_{\mathrm{p}}$ that determines the emptying of the reservoirs. As a matter of fact, the Nash IUH accounts for the physical characteristics of the basin that influence the flood generating processes (slope, morphology, vegetation cover, average density of the drainage network, etc.). Finally, to compute the total stormwater runoff at the outlet of the basin in $\mathrm{mm} / \mathrm{h}$, it is necessary to multiply the hourly effective rainfall $R_{\text {eff }}$ (assumed to be uniformly distributed in space over a defined period of time) by the Nash IUH $u(t)$. In order to retrieve the effective rainfall $R_{\text {eff }}$, a third parameter needs to be taken into account, namely the stormflow coefficient $c$, defined as the ratio between stormflow and rainfall volumes, so that $R_{\mathrm{eff}}=c R$. Hence, the total stormwater runoff is obtained as follows:

$Q(t)=\int_{0}^{t} c R(t-\tau) u(\tau) d \tau$

The stormflow coefficient represents an event-dependent parameter and its variability from one event to another is very difficult to assess, particularly in ungauged catchments. In humid temperate hydrologic regimes of north western Europe, the dominant runoff-generating process is saturation overland flow, caused by near-surface saturation conditions. The rainfall-infiltration-runoff partitioning, represented in the simplistic 3-parameter model by the value of $c$, obviously largely depends on the antecedent moisture conditions. Pfister et al. (2003) found a clear relationship between the saturation level (documented by water balance values), piezometric levels and runoff coefficients for the same catchment, supporting that the ratio between stormflow and rainfall reflects the actual degree of saturation of the basin and it is not significantly influenced by the rainfall structure once the soil is saturated.

As far as here, we computed the discharge of stormwater (event flow term). However, with the purpose of applying the methodology described in this paper, we also must take into account the discharge at the time $t_{0}$ when rainfall starts (pre-event flow term), in order to generate the whole flood hydrograph. As a matter of fact, the water volume that is obtained by merging the flood extent information extracted from remote sensing observations with the terrain topography includes pre-event and event water, thereby allowing the correction of the total runoff simulated by the model via a sequential updating of the stormflow coefficient (total runoff=pre-event runoff + event runoff, $c$ ).

\subsubsection{Hydraulic component of the modelling sequence}

Since in the area between Pfaffenthal and Mersch the flow direction is mainly parallel to the channel, the 2-D flow field that is typically related to riverbank overtopping can be accurately approximated by a 1-D representation (i.e. velocity components in directions other than the main flow direction are not accounted for). Thus, with a view to reducing computation time, the widely used Hydrologic Engineering Center River Analysis System - HEC-RAS - was set-up for 1-D river flow computation. However, it is worth mentioning that the methodology can also be extended to rivers characterized by a more complex geometry (which needs to be modelled 2-D), although further research needs to be done in this direction. The HEC-RAS model (HEC-RAS 4.0, 2008), developed by the Hydrologic Engineering Center belonging to the US Army Corps of Engineers, allows 1-D steady and unsteady flow calculations. The unsteady flow equation solver, UNET (Barkau, 1992), simulates 1-D unsteady flow through a full network of open channels. Setting up HEC-RAS requires a three-dimensional (3-D) geometry of the floodplain and channel, initial as well as boundary conditions, and hydraulic parameters (e.g. friction coefficients). In the studied river reach the channel and floodplain topography is represented by 172 3-D cross sections, placed perpendicularly to the stream centerline, derived from the LiDAR DEM and the bathymetric data. The boundary conditions of the model are as follows:

- upstream: the flow hydrograph at the hydrometric station in Pfaffenthal (R-R model output); 
- downstream: the normal depth (i.e. the slope of the channel bottom in the vicinity of the downstream boundary, which is often a good estimate of the slope of the water surface also in the framework of an unsteady flow analysis).

Furthermore, two tributaries, namely the Eisch and Mamer rivers, have their confluences with the Alzette River between two model cross sections, upstream of the town of Mersch. Nevertheless, since their contribution is not relevant for the flood extent information within the study area, the downstream boundary of the hydraulic model is defined upstream of the confluences, in order to simplify the analysis and restrain the number of inflows.

The initial condition is calculated by the model as a steady flow simulation using the discharge at Pfaffenthal gauging station (upstream boundary) at $t_{0}$.

As mentioned above, the implementation of a hydraulic model also requires the specification of roughness parameters: two Manning friction coefficients, one for the river channel, $n_{\mathrm{c}}$, and one for the floodplain, $n_{\mathrm{flp}}$, are considered. A single channel Manning coefficient is attributed to the entire reach in the model, as the channel aspect appeared homogeneous along the study area during field observations. Moreover, for the Alzette reach, Schumann et al. (2007a) demonstrated that a high number of acceptable flood simulations can be obtained at the reach-scale without spatially distributing channel roughness.

4.2 Water level estimation from remote sensing observations

The water level estimation methodology is described in detail by Hostache et al. (2006, 2009). It is composed of two main steps: i) SAR image processing in order to extract the flood extent limits that are relevant for water level estimation, ii) estimation of water levels by merging the relevant limits and a high resolution high accuracy Digital Elevation Model (DEM) under hydraulic coherence constraints.

In the first step of this method, the flood extent is derived from the SAR image using radiometric thresholding. This SAR-derived flood extent may be prone to local misclassifications that are mainly due to emerging objects that may mask water. Thereby, some flood extent limits may be erroneous. Since the water levels are estimated by merging the flood extent limits and the DEM, these erroneous limits, when taken into account, induce errors on the resulting water level estimates. As a consequence, we choose to remove from the flood extent limits those parts that are located in the vicinity of trees or buildings (mapped using aerial photographs and land use maps). The remaining limits, called "relevant" limits hereafter, shaped as small patches spatially distributed across the floodplain, will be used for water level estimation.
In the second step the "relevant" limits are merged with the underlying DEM in order to extract, for each pixel of these limits, the terrain elevation. It is worth noting that the DEM altimetric uncertainty (due to resolution and accuracy) and the flood extent limits spatial uncertainty are taken into account during this merging. The latter stem from three main sources: the image processing (i.e. the choice of the radiometric threshold values), the georeferencing and the spatial resolution of the SAR image. Next, by affecting the relevant limit pixels with cross sections of the hydraulic model geometry using a snapping distance equal to the mean cross section spacing, it is possible to estimate, for some model cross sections, water levels as intervals $I W L_{i}^{\mathrm{sat}}=\left[W L_{\mathrm{min}, i}^{\mathrm{sat}} ; W L_{\mathrm{max}, i}^{\mathrm{sat}}\right]$ (since numerous pixels of the relevant limits and thus numerous terrain elevation values are affected to a cross section). These intervals constitute primary water level estimates. Furthermore, it has been shown by Hostache et al. (2009) that these water level estimates have to be hydraulically constrained for more efficiency in the framework of hydraulic model calibration. Previously introduced by Raclot and Puech (2003), the hydraulic coherence algorithm is based on the hydraulic law stating that hydraulic energy decreases from upstream to downstream. Under the assumption of low velocity, which is acceptable in the Alzette floodplain, this statement can be simplified into a decrease of water level in the flow direction. Applied to the intervals of water level estimation, these constraints force a decrease upon the maxima $\left(W L_{\max , i}^{\mathrm{sat}}\right)$ from upstream to downstream and an increase upon the minima $\left(W L_{\mathrm{min}, i}^{\mathrm{sat}}\right)$ from downstream to upstream. This provides constrained water level estimates $I W L_{i}^{\mathrm{sat}}=\left[W L_{\mathrm{min}, i}^{\mathrm{sat}} ; W L_{\mathrm{max}, i}^{\mathrm{sat}}\right]$, called SAR derived water levels hereafter, that will be integrated with the calibration process.

The limits of applicability of the presented method are mainly related to the topography of the river valleys. As mentioned above, during the merging between the flood extension limits and the DEM, the uncertainties related to both the DEM and the SAR image are transferred to the water level estimates. Thus, hillslope areas imply important uncertainties on water level estimates due to the larger spread of possible elevation values inside the confidence interval of remote sensing-derived flood boundaries. As a result, the water level estimation method leads to reliable water level estimates only for relatively large and flat floodplains. Indeed, in the case of a narrow valley, uncertainties on the remote sensing-derived water levels are important.

\subsection{The value of SAR-derived water stages within an "all-} at-once" calibration scheme

As a first approach, the calibration of the modelling sequence is performed using a Monte Carlo procedure: each randomly sampled parameter set, containing three hydrologic $\left(c, t_{\mathrm{p}}, n\right)$ and two hydraulic parameters $\left(n_{\mathrm{c}}, n_{\mathrm{flp}}\right)$, is used to perform a 
simulation. It must be borne in mind that all parameters except the stormflow coefficient, which is event-dependent, are closely related to basin characteristics and can be considered constant.

The final output of the $\mathrm{H}-\mathrm{H}$ model, i.e. the simulated water levels, is compared to water levels estimated by the SAR flood images. Each simulation is stopped at time step $t_{\text {sat }}$ of the satellite overpass and simulated water levels are considered as matching the observations if they fall inside the interval of SAR-derived water levels $\left(W L_{\min , i}^{\mathrm{sat}}<W L_{i, t_{\mathrm{sat}}}^{\mathrm{sim}}<W L_{\max , i}^{\mathrm{sat}}\right)$. For the sake of simplification, all model runs inside the intervals are given a score of 1.

For each set of parameters the following performance criterion has been defined:

$$
P_{\text {sat }}=\sum_{i=1}^{N}\left(\frac{\Delta W L_{i}}{N}\right)
$$

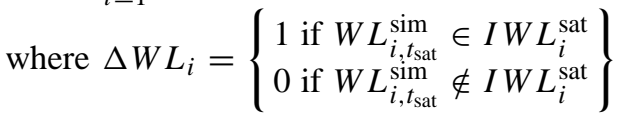

In Eq. (5), $W L_{i, t_{\mathrm{sat}}}^{\mathrm{sim}}$ is the simulated water level at the satellite overpass, $I W L_{i}^{\mathrm{sat}}=\left[W L_{\min , i}^{\mathrm{sat}} ; W L_{\max , i}^{\mathrm{sat}}\right]$ is the interval of the remote sensing derived water level on the model cross section $i$, and $N$ is the number of model cross sections where a SAR-derived water level is available. This performance criterion provides, for each model run (i.e. for each set of parameters), the number of cross sections (expressed as a fraction of the total), at which the simulated water level matches the observations.

4.4 The value of SAR-derived water stages within a sequential updating scheme

For the second calibration approach, variable parameters are separated from those that are assumed not to vary from one flood event to another. As a matter of fact, the parameters that are related to constant basin characteristics are calibrated using field observations of a first flood event, then transferred to another event for which SAR-derived water stages are available.

As mentioned earlier, $c$ is the only variable parameter within the hydrologic model since it depends on the soil moisture conditions that control rainfall-infiltration-runoff partitioning, whereas $n$ and $t_{\mathrm{p}}$ are related to the physiogeographical characteristics of the basin.

With respect to the hydraulic parameters, it is sensible to assume that, from a certain water stage onward, channel roughness does not vary in time, unless significant changes occur inside the river bed.
4.4.1 Calibration of model parameters using field observations

Since the presented H-H model is based on a loose coupling, it is sensible to use a first flood event to calibrate the hydrologic and the hydraulic model components independently.

The widely used Nash criterion (Nash and Sutcliffe, 1970) is applied to assess the performance of the hydrologic model. This criterion is well suited for a flood hydrograph evaluation since, in this case, it gives more weight to the highest values of discharge in the performance calculation. The flow hydrograph simulated by the Nash cascade at the outlet of the study drainage area is compared to the flow hydrograph observed in Pfaffenthal (with this definition the authors refer to the flow hydrograph calculated using the observed stage hydrograph and the rating curve).

$$
\text { Nash }=1-\frac{\sum_{t=t_{0}}^{t_{\text {end }}}\left(Q_{\text {sim }}(t)-Q_{\text {obs }}(t)\right)^{2}}{\sum_{t=t_{0}}^{t_{\text {end }}}\left(Q_{\text {sim }}(t)-\overline{Q_{\mathrm{obs}}}\right)^{2}}
$$

In Eq. (6) $Q_{\mathrm{obs}}(t)$ and $Q_{\text {sim }}(t)$ are the observed and simulated discharges at time $t$, respectively, expressed in $\mathrm{mm} / \mathrm{h}$. $t_{0}$ and $t_{\text {end }}$ are the starting and ending simulation time; $\overline{Q_{\text {obs }}}$ is the observed mean discharge in $\mathrm{mm} / \mathrm{h}$ between $t_{0}$ and $t_{\mathrm{end}}$. The Nash criterion describes how the R-R model performs as compared to a knowledgeless model that only reproduces the mean of the observed streamflow. A positive number indicates that it does better ( 1 is a perfect fit), while a negative number indicates that it performs worse.

In order to calibrate the hydraulic model, the observed flow hydrograph is used as the upstream boundary condition. The objective function for the hydraulic model is the root mean squared error (RMSE) between the simulated and observed water stages at six hydrometric stations along the river reach.

RMSE $_{\text {global }}=\sqrt{\sum_{i=1}^{N-h s s} \frac{\left(\sum_{t=t_{0}}^{t_{\text {end }}}\left(H_{\text {sim }}(t, i)-H_{\text {obs }}(t, i)\right)^{2}\right)}{\left(t_{\text {end }}-t_{0}+1\right) N_{-} h s}}$

In Eq. (7) $H_{\text {obs }}(t, i)$ and $H_{\text {sim }}(t, i)$ are the observed and simulated water levels at time $t$ and hydrometric station $i$, respectively, expressed in m. $t_{0}$ and $t_{\text {end }}$ are the starting and ending simulation time, while $N \_h s$ is the number of hydrometric stations. The RMSE is equal to 0 if the observed and simulated hydrographs fit perfectly and the more divergent these hydrographs, the higher the RMSE.

\subsubsection{Updating of the stormflow coefficient using SAR im- ages}

This step of the methodology aims at assessing the saturation status of the river basin in order to reduce the volume errors 
in the simulated inflow, namely the flow hydrograph at Pfaffenthal, using the remote sensing-derived water levels. To achieve this goal the modelling sequence is set-up using the values of the hydrologic parameters $n$ and $t_{\mathrm{p}}$ and the Manning coefficients found for the event used in Sect. 4.4.1 and the stormflow coefficient is updated for another event using remote sensing observations.

The evaluation procedure is the same as the one described in Sect. 4.3 and the performance $P_{\text {sat }}$ (see Eq. 3) represents, for each value of $c$, the number of cross sections (expressed as a fraction of the total), at which the simulated water level matches the observations.

Additionally, stormflow coefficients providing water levels within the uncertainty interval of SAR-derived water stages $\left(I W L_{i}^{\text {sat }}\right)$ are plotted for each cross section over the entire reach. This "local" evaluation gives an appreciation of the variability of likely $c$ values depending on which cross section is considered and represents a helpful tool to better understand the results obtained with the previous "average" evaluation.

\section{Results}

5.1 Water level estimation from remote sensing observations

The water level estimation method presented in Sect. 4.2 has been applied to the ERS and the ENVISAT images using the LiDAR DEM as source of terrain elevation data. Ground surveyed flood extent marks located in areas without trees or buildings have been used to validate the flood boundaries estimated using the ENVISAT image in the first step of the procedure (see Sect. 3). It is worth mentioning that the field campaign was undertaken close to the flood peak, that corresponds to the ENVISAT satellite overpass time. 92\% of the ground surveyed flood marks lie within the confidence bounds of the SAR-derived flood boundary. Moreover, the mean distance between the marks that lie outside this interval and these limits is equal to $4 \mathrm{~m}$. This is lower than the coordinate accuracy of these points (accuracy of the GPS used to calculate the flood extent marks is of approximately $5 \mathrm{~m})$. To characterize the uncertainty of the water levels resulting from the second step of the procedure, the half mean range $\frac{\operatorname{mean}\left(W L_{\max }-W L_{\min }\right)}{2}$ of the intervals of water levels has been calculated. This "mean uncertainty" is equal to $\pm 43 \mathrm{~cm}$ for the ERS image and $\pm 54 \mathrm{~cm}$ for the ENVISAT image. Furthermore, since the ENVISAT image has been acquired close to peak discharge, the ENVISAT-derived water levels have been compared to seven ground measured high water marks (see Sect. 3). This comparison shows the reliability of the water level estimation method, since all these high water marks are included inside the possibilistic intervals of SARderived water levels. This result validates the hypothesis of the method stating that the real water level matches the SARderived water levels.

\subsection{The "all-at-once" calibration scheme}

The aim of the first calibration approach was to verify the possibility to calibrate the modelling sequence for the 2003 flood event in one go by means of remote sensing-derived water levels.

To set up the hydrologic model, hourly rainfall data observed in Livange between the 1st and 7th of January 2003 and the pre-event flow measured in Pfaffenthal at the beginning of the storm event $(0.11 \mathrm{~mm} / \mathrm{h})$ were used.

The hydraulic model was set up as proposed in Sect. 4 with the upstream boundary condition being output by the hydrologic model and the downstream boundary condition being the normal depth.

For the calibration procedure, 3000 sets of parameters were randomly generated within the following intervals of plausible values:

- for the stormflow coefficient: $c \in[0.1 ; 0.9]$;

- for the number of reservoirs: $n \in[1.1 ; 5]$;

- for the recession time constant: $t_{p} \in[1 ; 30]$;

- for the channel Manning coefficient: $n_{\mathrm{c}} \in[0.01 ; 0.1]$;

- for the floodplain Manning coefficient: $n_{\mathrm{flp}} \in[0.01 ; 0.2]$.

For each generated set of parameters, one run of the modelling chain was performed for the period between the $1 \mathrm{st}$ and 7th of January 2003.

A brief clarification about the choice of assigning floating values to the parameter $n$ needs to be done: in this study the authors do not mean to represent the basin as a physical cascade of reservoirs, but rather to compute the discharge at the outlet through the equations that are the basis of the Nash hydrologic model.

The calibration was performed using both the ENVISAT and the ERS-2 images. In both cases, the comparison between simulated and remote sensing-derived water levels did not provide satisfactory results since none of the parameters became identifiable. According to the equifinality concept (Beven, 2006), the nonlinearity of the model structure causes a compensation phenomenon between parameters, which leads to multiple parameter combinations giving similar performances with respect to the reference data at hand. As a matter of fact, a decrease of $c$ leads to a decrease of the discharge but at the same time an increase of the roughness value leads to an increases of the water level. This result highlights the necessity to reduce the number of parameters to be calibrated. Two snap shots of flood extent derived from satellite imagery do not contain enough information to unambiguously calibrate a multitude of model parameters. 
Table 2. Results of the test for the transferability of $n$ and $t_{\mathrm{p}}$.

\begin{tabular}{llllll}
\hline Flood event & $\begin{array}{l}\text { Total rainfall } \\
(\mathrm{mm})\end{array}$ & $\begin{array}{l}\text { Peak discharge } \\
(\mathrm{mm} / \mathrm{h})\end{array}$ & $\begin{array}{l}\text { Pre-event flow } \\
(\mathrm{mm} / \mathrm{h})\end{array}$ & $\begin{array}{l}\text { Return period } \\
\text { (years })\end{array}$ & Nash coefficient \\
\hline February 1997 & 54.48 & 0.592 & 0.055 & 4 & 0.949 \\
November 1998 & 25.32 & 0.557 & 0.132 & 3 & 0.709 \\
December 1999 (I) & 65.7 & 0.549 & 0.031 & 3 & 0.916 \\
December 1999 (II) & 61.53 & 0.567 & 0.063 & 3 & 0.917 \\
January 2001 & 47.85 & 0.685 & 0.112 & 8 & 0.903 \\
\hline
\end{tabular}

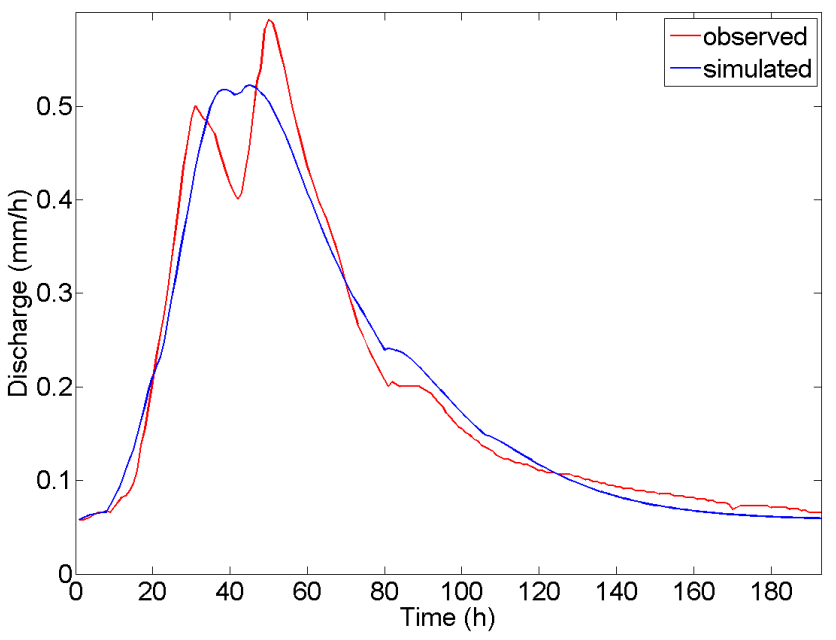

Fig. 3. Observed and simulated flow hydrographs at Pfaffenthal for the 2007 flood event.

This result is well in line with previous studies on the same river reach demonstrating the equifinality phenomenon in hydraulic model calibration with remote sensing-derived flood information (e.g. Hostache et al., 2006). To circumvent this problem the number of flood images needs to be increased and complementary data sets need to be considered for model calibration.

\subsection{The sequential updating scheme}

The second approach focuses on estimating the saturation status of the river basin by distinguishing between eventdependent and constant parameters. As a matter of fact the values of $n$ and $t_{\mathrm{p}}$ calibrated using the 2007 event can be transferred to the 2003 test event, as well as the calibrated values of the roughness, whereas the parameter $c$ needs to be updated, as it is event-specific and expresses indirectly the soil moisture conditions during the 2007 flood event. To validate the hypothesis of $n$ and $t_{\mathrm{p}}$ being invariant in time, a test has been done with the rainfall-runoff data recorded during five additional events. The Nash cascade algorithm was run for each test event using the same $n$ and $t_{\mathrm{p}}$ found for 2007 and varying only $c$ in order to optimize the model re- sults. The analysis of the performances obtained comparing the observed and the simulated flow hydrographs (see Table 2) leads to the conclusion that it is sensible to support the transferability of $n$ and $t_{\mathrm{p}}$ from one event to another.

The Nash cascade was set up using as input the hourly rain data observed in Livange between the 17th and the 25th of January 2007 and a value of pre-event flow in Pfaffenthal of $0.06 \mathrm{~mm} / \mathrm{h}$. Then, 10000 sets of hydrologic parameters were randomly generated within the same intervals as those used for the all-at-once scheme and for each set, one run of the hydrologic model was performed. Then, for each run, the computed flow hydrograph is compared with the one observed in Pfaffenthal using the Nash coefficient as a measure of model performance. The parameter set giving the best fit (Fig. 3) with a Nash efficiency of 0.95 provides $c=0.73, n=1.71$ and $t_{\mathrm{p}}=12.11 \mathrm{~h}$.

The hydraulic model was set up using the 2007 flood event data. For the calibration, 1000 parameter sets were randomly generated within the friction intervals defined in Sect. 5.2. Next, for each generated set of parameters, one hydraulic model run was performed for 2007 and the results were compared with field observations. For this flood event, stage hydrograph records in Pfaffenthal (upstream), Walferdange, Steinsel, Hunsdorf and Lintgen were available. As a performance criterion, a global RMSE, taking into account all five hydrometric stations, was used. The hydraulic parameters set giving the best fit at the majority of the stations (see Fig. 4) was $n_{\mathrm{c}}=0.047 ; n_{\mathrm{flp}}=0.184$. These estimates are supported by an evaluation based on an empirical approach suggested by Arcement and Schneider (1984) for 1-D open channel flow. The methodology is based on a step-by-step procedure, where a base value of roughness is assigned and some adjustments for various roughness factors are made in order to obtain a final value. As it is assumed that the river bed did not change significantly over the last years, it is sensible to retain the roughness values of the 2007 event for the 2003 test event.

After calibrating the coupled H-H model on the 2007 event, the parameter values obtained are transferred to the 2003 event, except for $c$, as it is event-specific and needs to be updated using the SAR-derived water stages:

- hydrologic parameters: $n=1.71, t_{\mathrm{p}}=12.11 \mathrm{~h}$; 


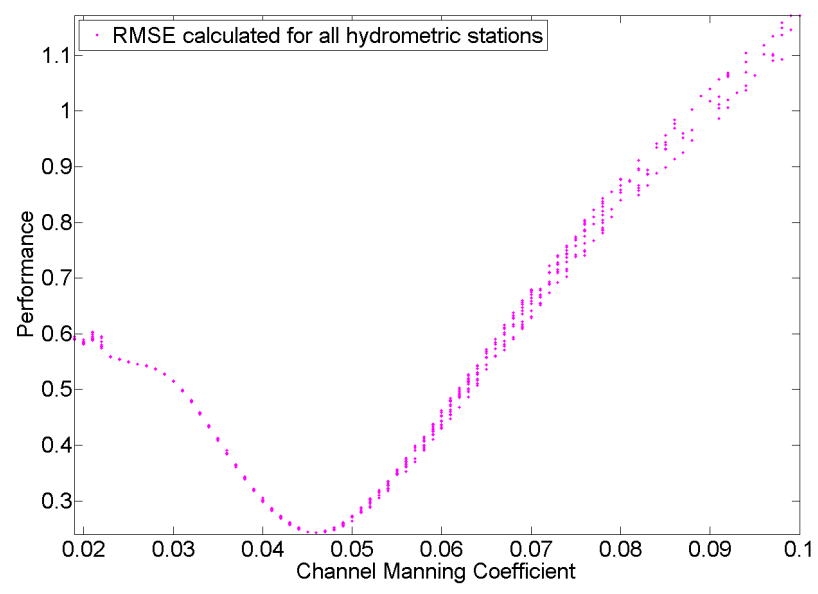

Fig. 4. Relationship between the channel Manning coefficient and the model RMSE calculated for all hydrometric stations.

- hydraulic parameters: $n_{\mathrm{c}}=0.047, n_{\mathrm{flp}}=0.184$.

1000 values of $c$ were randomly generated within the interval $[0.1 ; 0.9]$ and for each value one run of the modelling sequence was performed for the January 2003 event (1-7 January).

The plots (a) and (b) in Fig. 5 show the water lines simulated by the model for the whole range of stormflow coefficients and the water levels estimated using the ENVISAT and the ERS-2 images, respectively. For both images, the uncertainty related to the SAR-derived water levels has the same order of magnitude than the spread of water surface lines simulated with different values of $c$.

The dotty plots (a) and (b) in Fig. 6 show the performance $P_{\text {sat }}$ of the model (see Eq. 5) for the ENVISAT and ERS2 images, respectively. In these pictures, each dot corresponds to the evaluation of the model result over the entire river reach for one value of $c$. The higher $P_{\text {sat }}$, the higher the number of cross sections providing simulated water stages matching the observations. Due to the uncertainty related to the remote sensing-derived water levels, both plots are not peaky but almost flat at the top. In other words, a straightforward evaluation and identification of a "best" value of $c$ is not really possible. However, using this "average" evaluation, it is possible to significantly constrain the range of likely values of $c$ with respect to the whole interval of physically plausible values. When comparing the water levels derived from the ENVISAT image with those simulated by the model, the values of $\mathrm{c}$ within the interval $[0.80 ; 0.81]$ all give the best score $\left(P_{\text {sat }}=0.84\right)$. Using the ERS-2 image, the performances decrease drastically, but it is still possible to identify the range of $c$ giving the best result: $[0.68 ; 0.86]$ with $P_{\text {sat }}=0.58$.

To validate these results the actual value of the stormflow coefficient was calculated by simply dividing the volume of runoff by the volume of rainfall, obtaining $c_{\text {act }}=0.71$. With respect to this value, the evaluation based on the ENVISAT image leads to an overestimation of the stormflow coefficient
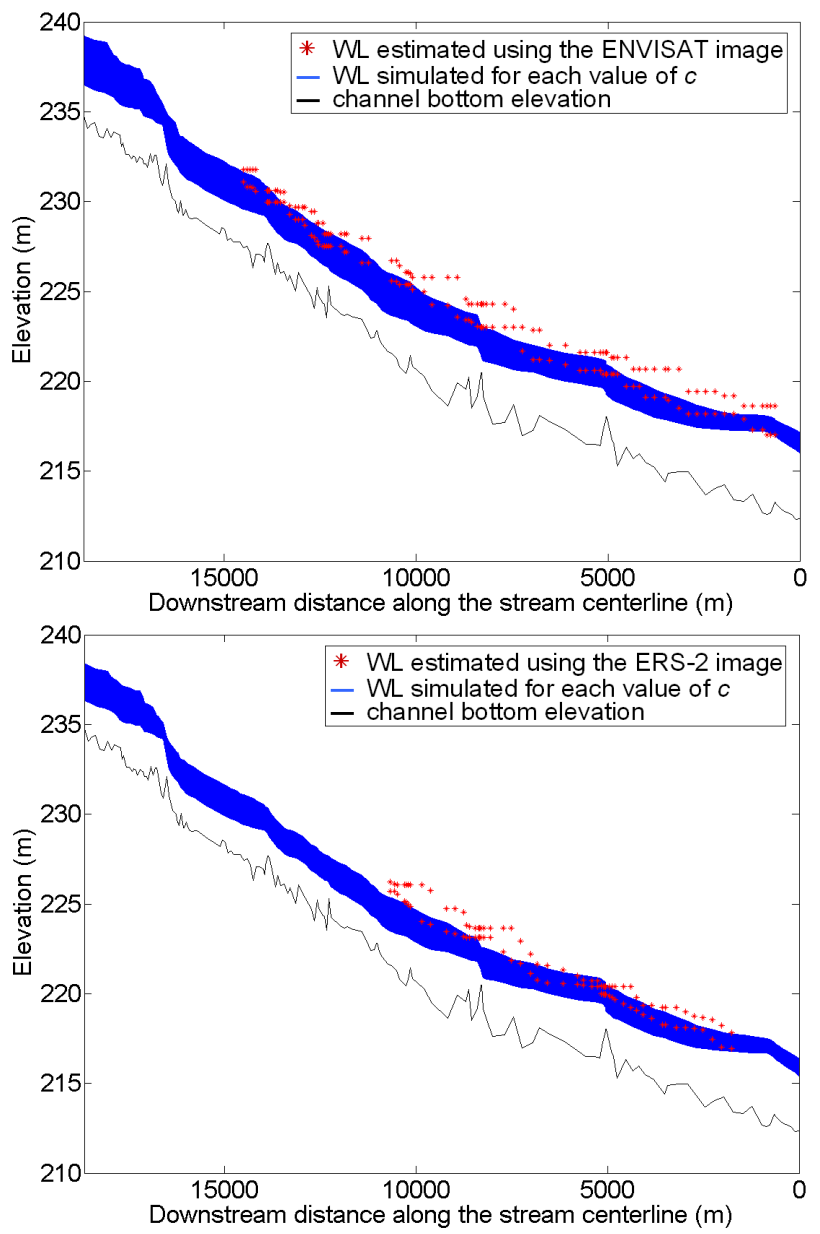

Fig. 5. Comparison between the water surface lines simulated by the model and the water levels estimated using the ENVISAT and the ERS-2 images, respectively plots (a) and (b).

$\left(c_{\text {best }}=[0.80 ; 0.81]\right.$ vs. $\left.c_{\text {act }}=0.71\right)$, although the model performance corresponding to $c_{\text {act }}\left(P_{\text {sat }}=0.80\right)$ is still very close to the maximum. Using the ERS-2 image, the range of $c$ giving the best performance is less constrained with respect to that obtained by ENVISAT, and the actual value of $c$ falls inside.

In order to better understand the previous results, a "local" (cross section by cross section) evaluation has been performed: the plots (a) and (b) in Fig. 7 show the ranges of likely $c$ values estimated over each single cross section using the ENVISAT and the ERS-2 images, respectively. From a visual analysis of the plots, two peculiarities are observable.

i) For almost all cross sections, the range of stormflow coefficients giving simulated water levels that are within the uncertainty interval of SAR-derived water level estimates is quite wide. This is a consequence of the fact that the spread of the water lines simulated using different values of $c$ has the same order of magnitude than the uncertainty interval related to the estimation of the water levels from the SAR images (see Sect. 5.1). 

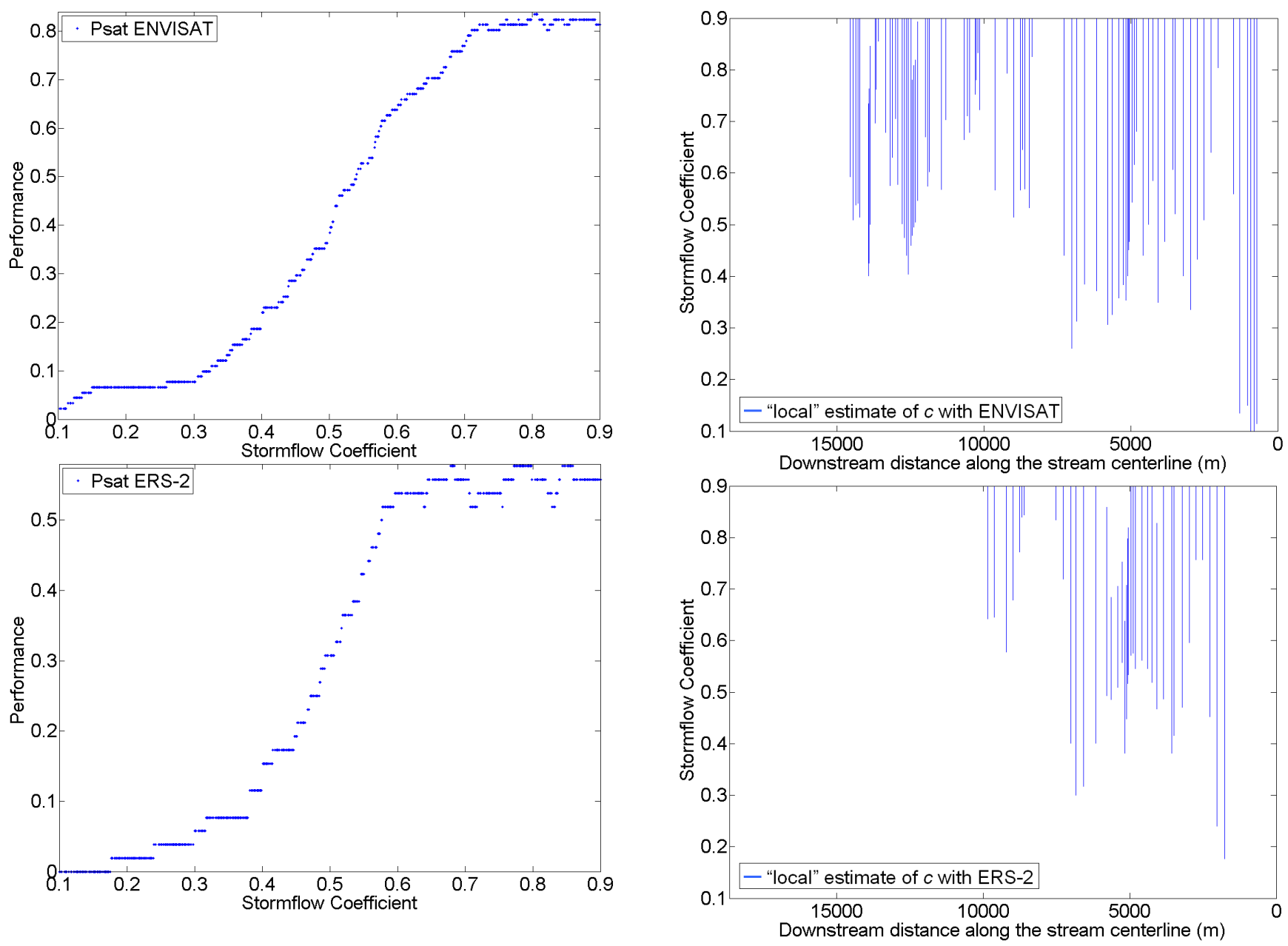

Fig. 6. Relationship between the stormflow coefficient and the model performance calculated over the entire river reach, for the ENVISAT and the ERS-2 images, respectively plots (a) and (b).

ii) Comparing the ranges of stormflow coefficients corresponding to different cross sections, the intervals do not overlap over the entire reach whereas they should unless major inflows were not considered. As a matter of fact, these results might appear incoherent because in theory there should be a single value of stormflow coefficient. These incoherences are probably due to local errors and uncertainties in the model and/or in the dataset.

\section{Discussion and conclusions}

In the framework of this study, we tried to answer the following question: assuming there is a need to provide prediction of flood extent in an ungauged catchment, what minimum amount of data do we need to collect in order to come up with useful and reliable predictions? To this we would answer the following:

Fig. 7. "Local" evaluation using the ENVISAT and the ERS-2 images, respectively plots (a) and (b): the blue lines represent the values of $c$ giving simulated water levels within the uncertainty interval of SAR-derived water stages for each cross section.

- a continuously recording raingauge (an alternative would be to rely on the outputs of atmospheric models to provide the forcings, but with the associated uncertainty expected to be very high);

- a constant value of pre-event flow (in this study we used the discharge measured at Pfaffenthal at time $t_{0}$ because we had this information at our disposal; alternatively one can use specific discharge recorded at another streamgauge within the region, or an average mean winter discharge of a sample of gauges within the region);

- the geometry of the river channel and the associated floodplain (although LiDAR techniques are nowadays a useful tool to acquire fine topographic and bathymetric information without intensive field work, here the alternative would be the use of a global remote 
sensing-derived DEM such as the SRTM, cf. Schumann et al., 2008a);

- a single flood event recorded via streamgauges in order to provide the data that allows calibrating both the hydrologic and the hydraulic components of a flood forecasting system;

- remote sensing observations of floods in order to monitor effective rainfall amounts, thereby providing a sequential update of the stormflow coefficient of the hydrologic model.

In other words, once the sequence of models is calibrated using a well-documented flood event, only precipitation (via raingauges), a constant value of pre-event flow (via streamgauges located outside the area of interest, i.e. the floodplain) and flood extent (via remote sensing observations) are needed to provide flood forecasts. Thus, we argue that our approach can be applied to a poorly instrumented catchment where no streamgauges are permanently installed and rainfall is the unique information that is continuously recorded. This argument allows us presenting our methodology as a step in the direction of the PUB initiative of the IAHS (International Association of Hydrological Sciences), although we admit that the link is disputable since PUB refers to prediction of streamflow, which is not based on the availability of measured data (PUB Sciences and Implementation Plan, 2003). One might wonder why the use of discharge to update the state of hydrologic models has been left out of the discussion. There is no doubt that, in presence of permanent stream gauges at the outlet of the basin, the assimilation of discharge data would be preferable with respect to a hydrologic-hydraulic model coupling and that it would provide better results (e.g. Aubert et al., 2003), but it does not fall within the working hypothesis of this study. As a matter of fact, we suppose that in our test area the discharge data are available only for a single well-documented flood event (the discharge data calculated during the case study event that had occurred on January 2003 were only used to validate the model results). We demonstrate that once we measured the discharge at the upstream boundary of the hydraulic model for one flood event and used the corresponding data to calibrate both the hydrologic and the hydraulic model components, we do not need this information anymore and the approach can be applied to any other flood event that is observed with SAR imagery. Hence, this approach must not be viewed as an alternative to the use of discharge data, but rather as a helpful methodology in case of a lack of discharge time series.

Hereby, we would like to highlight the innovative approach we used in this paper to calibrate a loosely coupled hydrologic-hydraulic (H-H) model taking advantage of SARderived water stages. Instead of using water stage data from spaceborne radar to calibrate effective roughness coefficients for the hydraulic model as has been done in previous studies, this study introduces a stepped scheme for calibrating coupled H-H models with SAR water stages whereby an aggregated variable of the basin saturation status, namely the event-dependent stormflow coefficient, can be sequentially updated. The results show that this approach is preferable to a more conventional "all-at-once" calibration approach since the SAR-derived flood information at hand does not allow by itself unambiguously calibrating a multitude of model parameters because the "mean u ncertainty" related to the water level estimation (see Sect. 5.1) is too high for this purpose. Moreover, it is shown that, although an "average" evaluation over the entire river reach does not lead to the identification of one "best" value of the stormflow coefficient, it allows to estimate a constrained range of values all giving equally high performance and being reasonably close to the true value as it was obtained from in situ rainfall and streamflow measurements. Furthermore, it is believed that multiple images of the same event acquired at different times help to cross-validate the results.

In this paper we intended to test an alternative approach with respect to the studies on the value of remote sensing soil moisture for hydrologic modeling. By using remote sensing data to monitor open water storage, we exploited a direct way for assessing the ratio between incident and effective rainfall. For a given precipitation amount, flood extent implicitly represents the readiness of a basin to generate runoff, thus we can state that the surface water volume represents the response of the river basin to a storm event. As a matter of fact, we updated an aggregated hydrologic variable (i.e. the stormflow coefficient) with remote sensing-derived water levels. This is the major advantage of the presented methodology with respect to more conventional methods based on the updating of hydrologic models by the means of remote sensing-derived soil moisture. As a matter of fact, the soil moisture is not directly related to the effective rainfall, thus this approach can lead to incorrect results stemming from parameters and forcing term errors, other than errors in the soil moisture retrieval using satellite imagery.

Among the shortcomings affecting the methodology presented in this paper, there is the fact that a quasi-continuous surface water monitoring requires a particular topographical scenario where changes in streamflow imply significant changes in flood extent. Moreover in complex river systems the source of errors leading to incorrect results is not known a priori, since they could be due to a wrong estimation of both inflows and channel roughness.

The suggested methodology might be seen as a first step toward a systematic remote sensing-based surface water monitoring system that may quasi-continuously provide valuable information for sequentially updating coupled $\mathrm{H}$ $\mathrm{H}$ models. The authors believe that they introduced a potentially useful calibration scheme for more complex modelling sequences where highly complex parameter interaction dictates the way models need to be calibrated. More 
traditional calibration may fail and thus more applicationand model-specific schemes are required. It is now widely recognised that (spaceborne) remote sensing offers ways to advance our understanding of natural processes and models and their evaluation. There is also little doubt that newly launched higher resolution satellites will further increase this support. However, more research is needed to better understand (i) how model parameters really interact and lead to an aggregated response (which we observe) and (ii) what information content in remotely sensed images is really needed to help achieve this.

Acknowledgements. This study was carried out in the framework of the "Hydrasens" project, funded by the National Research Fund (FNR) of the G. D. of Luxembourg and the STEREO II research program for Earth Observation of the Belgian Federal Science Policy Office (BELSPO).

Edited by: W. Wagner

\section{References}

Andreadis, K. M., Clark, E. A., Lettenmaier, D. P., and Alsdorf, D. E.: Prospects for river discharge and depth estimation through assimilation of swath-altimetry into a rasterbased hydrodynamics model, Geophys. Res. Lett., 34, L10403, doi:10.1029/2007GL029721, 2007.

Arcement Jr., G. J. and Schneider, V. R.: Guide for selecting Manning's roughness coefficients for natural channels and floodplains, online available at: http://www.fhwa.dot.gov/bridge/ wsp2339.pdf, 1984.

Aronica, G., Bates, P. D., and Horritt, M. S.: Assessing the uncertainty in distributed model predictions using observed binary pattern information within GLUE, Hydrol. Proc., 16, 2001-2016, 2002.

Aubert, D., Loumagne, C., and Oudin, L.: Sequential assimilation of soil moisture and streamflow data in a conceptual rainfallrunoff model, J. Hydrol., 280, 145-161, 2003.

Barkau, R. L.: One-dimensional unsteady flow through a full network of open channels, (Computer Program), UNET, St. Louis, MO, USA, 1992.

Beven, K.: A manifesto for the equifinality thesis, J. Hydrol., 320, 18-36, 2006.

Brocca, L., Melone, F., Moramarco, T., and Morbidelli, R.: Antecedent wetness conditions based on ERS scatterometer data, J. Hydrol., 364, 73-87, 2009.

François, C., Quesney, A., and Ottle, C.: Sequential assimilation of ERS-1 SAR data into a coupled land surface-hydrological model using an extended Kalman filter, Hydrometeorol., 4, 473-487, 2003.

HEC-RAS 4.0: online available at: http://www.hec.usace.army.mil/ software/hec-ras/documents/HEC-RAS_4.0_Reference_Manual. pdf, last access: 5 May 2008.

Hostache, R., Puech, C., Schumann, G., and Matgen, P.: Estimation de niveaux deau en plaine inondée à partir dimages satellites radar et de données topographiques fines, Télédétection, 6, 325$343,2006$.
Hostache, R., Matgen, P., Schumann, G., Puech, C., Hoffmann, L. and Pfister, L.: Water level estimation and reduction of hydraulic model calibration uncertainties using satellite SAR images of floods, IEEE T. Geosci. Remote, 47, 431-441, 2009.

Le Hégarat-Mascle, S., Zribi, M., Alem, F., Weisse, A., and Loumagne, C.: Soil moisture estimation from ERS/SAR data: Toward an operational methodology, IEEE T. Geosci. Remote, 40, 2647-2658, 2002.

Mason, D. C., Horritt, M. S., Dall'Amico, J. T., Scott, T. R., and Bates, P. D.: Floodplain friction parametrization in twodimensional river flood models using vegetation heights derived from airborne scanning laser altimetry, Hydrol. Proc., 17, 17111732, 2003.

Matgen, P., Henry, J. B., Hoffmann, L., and Pfister, L.: Assimilation of remotely sensed soil saturation levels in conceptual rainfallrunoff models, in: Predictions in Ungauged Basins: Promises and Progress, Proceedings of symposium S7 held during the Seventh IAHS Scientific Assembly, Foz do Iguaçu, Brazil, April 2005, IAHS Publications, 303, 226-234, 2005.

Nash, J.: A unit hydrograph study with particular reference to British catchments, P. I. Civil. Eng., 17, 249-282, 1960.

Nash, J. and Sutcliffe, J.: River flow forecasting through conceptual models, 1. A discussion of principles, J. Hydrol., 10, 282-290, 1970.

Oberstadler, R., Hönsch, H., and Huth, D.: Assessment of the mapping capabilities of ERS-1 SAR data for flood mapping: a case study in Germany, Hydrol. Proc., 10, 1415-1425, 1997.

Pappenberger, F., Matgen, P., Beven, K., Henry, J. B., Pfister, L., and de Fraipont, P.: Influence of uncertain boundary conditions and model structure on flood inundation predictions, Adv. Water Resour., 29, 1430-1449, 2006.

Pauwels, V. R. N., Hoeben, R., Verhoest, N. E. C., and De Troch, F. P.: The importance of the spatial patterns of remotely sensed soil moisture in the improvement of discharge predictions for small-scale basins through data assimilation, J. Hydrol., 251, 88102, 2001.

Pfister, L., Drogue, G., El Idrissi, A., Humbert, J., Iffly, J. F., Matgen, P., and Hoffmann, L.: Predicting peak discharge through empirical relationships between rainfall, groundwater level and basin humidity in the Alzette River basin, Grand-Duchy of Luxembourg, J. Hydrol. Hydromech., 53, 210-220, 2003.

PUB Sciences and Implementation Plan: online available at: http: //pub.iwmi.org/UI/Images/PUB_Science_Plan_V_5.pdf, 2003.

Quesney, A., Le Hégarat-Mascle, S., Tacomnet, O., Vidal-Madjar, D., Wigneron, J. P., Loumagne, C., and Normand, M.: Estimation of watershed soil moisture index from ERS/SAR data, Remote Sens. Environ., 72, 290-303, 2000.

Raclot, D. and Puech, C.: What does AI contribute to hydrology? Aerial photos and flood levels, Appl. Artif. Intell., 17, 71-86, 2003.

Schumann, G., Matgen, P., Hoffmann, L., Hostache, R., Pappenberger, F., and Pfister, L.: Deriving distributed roughness values from satellite radar data for flood inundation modelling, J. Hydrol., 344, 96-111, 2007a.

Schumann, G., Matgen, P., Pappenberger, F., Hostache, R., Puech, C., Hoffmann, L., and Pfister, L.: High resolution 3-D flood information from radar for effective flood hazard management, IEEE T. Geosci. Remote, 45, 1715-1725, $2007 \mathrm{~b}$.

Schumann, G., Matgen, P., Cutler, M. E. J., Black, A., and Pfis- 
ter, L.: Comparison of remotely sensed water stages from LiDAR, topographic contours and SRTM, ISPRS J. Photogramm., 63, 283-296, doi:10.1016/j.isprsjprs.2007.09.004, 2008a.

Schumann, G., Matgen, P., and Pappenberger, F.: Conditioning water stages from satellite imagery on uncertain data points, IEEE Geosci. Remote Sens., 5, 810-813, 2008 b.

Sherman, L. K.: Stream-flow from rainfall by the Unit Graph Method, Eng. News Rec., 108, 501-505, 1932.

Smith, L. C.: Satellite remote sensing of river inundation area, stage and discharge: a review, Hydrol. Proc., 11, 1427-1439, 1997.

van den Bos, R., Hoffmann, L., Juilleret, J., Matgen, P., and Pfister, L.: Regional runoff prediction through aggregation of first-order hydrological process knowledge: a case study, Hydrol. Sci. J., 51, 1021-1038, 2006.
Wagner, W. and Pathe, C.: Has SAR failed in soil moisture retrieval?, in: Proceedings of the ENVISAT \& ERS Symposium, Salzburg, Austria, 6-10 September, 2004.

Walker, J. P., Houser, P. R., and Willgoose, G. R.: Active microwave remote sensing for soil moisture measurement: a field evaluation using ERS-2, Hydrol. Proc., 18, 1975-1997, 2004.

Werner, M., Blazkova, S., and Petr, J.: Spatially distributed observations in constraining inundation modeling uncertainties, Hydrol. Proc., 19, 3081-3096, 2005.

Zribi, M., Baghdadi, N., Holah, N., and Fafin, O.: New methodology for soil surface moisture estimation and its application to ENVISAT-ASAR multi-incidence data inversion, Remote Sens. Environ., 96, 485-496, 2005. 